\title{
Analysing the Shadows: Private Tutoring as a Descriptor of the Education System in Georgia
}

\author{
Tamar Bregvadze ${ }^{1}$ \\ ${ }^{1}$ Ilia State University, Tbilisi, Georgia \\ Correspondence: Tamar Bregvadze, Ilia State University, 5, Kavtaradze str., Tbilisi 0186, Georgia. Tel: \\ 995-599-515-785. E-mail: tamar_bregvadze@iliauni.edu.ge
}

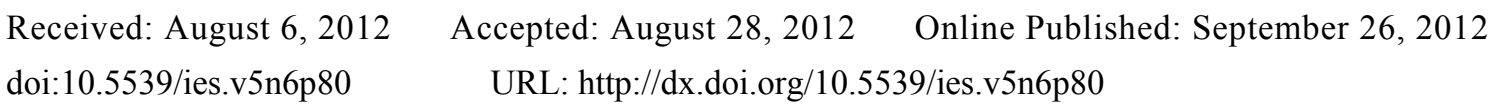

\begin{abstract}
During the past decade Georgia has received strong international support for education reform, and it represents an interesting case by which the effectiveness of particular interventions in the region can be assessed. Most attempts to analyse progress within the system have so far been concentrated on two aspects of formal education: private and public schools. This article analyses the dynamics of change from a different angle, and focuses attention on a third important, but shadow aspect of the education system: supplementary private tutoring. A representative survey of parents of school-age children and university entrants describes the scope, drivers and effects of private tutoring in Georgia. These findings are then used to analyse the effectiveness of the system in terms of the criteria of quality and equity.
\end{abstract}

Keywords: general education, education reform, private tutoring, equity, quality of general education

\section{Introduction}

Georgia, like many other countries in the world, is experiencing substantial changes within the general education system, and it receives considerable international support for these reforms. Identifying measured change in the effectiveness of education reform is of interest to policy makers and scholars, both locally and internationally.

In an attempt to understand the dynamics of change in education systems, policy analysts and researchers mostly concentrate attention on two aspects of formal education: private and public schools. The current study represents a different perspective on the analyses of the effectiveness of general education reform in Georgia by taking a closer look at what is considered "as a third and important education sector along with public and private education: the private tutoring industry" (Dang \& Rogers, 2008).

Private tutoring (PT) is defined in this article as "fee-based supplementary instruction to children in academic subjects that they study in the mainstream education system" (Silova, Budiene, \& Bray, 2006). The growth of this phenomenon is evident in many countries of the world: across Europe (Bray, 2011), Asia (Bray \& Lykins, 2012) and the United States (Buchmann, Condron, \& Roscigno, 2010). The academic literature suggests that in many cases the phenomenon appears in response to certain drawbacks of formal education systems, and itself influences the system in many different ways (Stevenson \& Baker, 1992, Bray, 2011, Silova et al., 2006, Baker \& LeTendre, 2005). Therefore, if viewed as a part of the whole education system, private tutoring can broaden our knowledge on the functionality of education systems and help us better understand the effect of current policy and the politics of education.

The interplay of the characteristics of formal education systems and PT is acknowledged, but this has not yet been studied in detail in different parts of the world. Understanding which factors propel certain countries to develop extensive shadow education aimed at specific educational goals, and how PT influences the outcomes of formal education in particular contexts, is crucial for education policy development as well as for a deeper theoretical understanding of the phenomenon (Baker, Akiba, LeTendre, \& Wiseman, 2001).

The current study adds to existing knowledge in the field through analysing the interrelation of the formal education system and the PT phenomenon in Georgia. This study describes and analyses the scope of PT after the last wave of education reforms in the country initiated in 2004. A nation-wide survey of parents of school-age children and university entrants provides information on the perceived main drivers and the effects of private tutoring, and identifies the scope and patterns of PT by levels of general education, the rural-urban divide 
and the family income of consumers of the service. The findings of this survey are then used to evaluate the effectiveness of the general education system against the criteria of quality and equity.

\subsection{PT as a Descriptor of Education Systems (Conceptual Framework)}

One of the reasons why Private Tutoring is frequently referred to in literature as "shadow education" (Bray, 2003; Baker \& LeTendre, 2005) is that it never stands alone as an independent educational activity, but coexists with mainstream education.

This phenomenon interacts with mainstream education systems in two ways:

On the one hand, it often emerges as a response to specific problems in the functionality of a formal education system because, like any other shadow, PT reflects many important characteristics of the object and mirrors it (Bray, 2011). There are also other drivers of PT, such as social, economic and cultural factors, but observers of the phenomenon throughout the world have commented on the importance of the characteristics of formal education systems in shaping the nature and scale of private supplementary tutoring and even in "determining its structure, value, and eventual impact" (Baker et al., 2001).

On the other hand, private tutoring itself influences the mainstream education process. In many cases it deepens inequalities in access to quality education. In this sense, unlike most shadows, private tutoring is not just a passive entity, but may negatively affect the very body that it imitates (Bray, 2009).

Therefore, understanding the causes and effects of PT may provide valuable information on the current state of education systems. Examining the effects of PT helps us evaluate the system against the criterion of equity, while analysing the drivers of PT informs us about the quality of the outputs of a general education (GE) system.

\subsubsection{Education System as a Driver of PT}

There are many characteristics of an education system that PT may respond to, including underfinancing of the system, corruption, ineffective teaching processes, and drawbacks in curriculum and assessment processes (Buchmann et al., 2010). However, the whole spectrum of different drivers related to system characteristics can be generalized as a single factor, that of the unsatisfactory quality of mainstream schooling.

From the perspective of systems theory, there are two main prerequisites of the quality of open systems: (i) the goals of the system are achievable through functioning of the system, and (ii) the goals of the system are consistent with the external requirements of the system environment, that is to say, of the larger systems to which a particular system belongs (Gharajedaghi \& Ackoff, 1984).

The two descriptors of functional open systems mentioned above can be applied to general education, and operationalized into two more precise indicators of the quality of mainstream schooling: (i) internal effectiveness, that is, the consistency of the actual outputs of the general education system with the requirements of framework curricular documents; and (ii) external relevance, that is, the consistency of the general education curriculum with the entrance requirements of the higher stages of formal education or of the labour market.

The data on private tutoring in the country can help researchers analyse the quality of general education systems from these two important perspectives, and the clue is in understanding the main drivers of a private tutoring service.

There are two main reasons why people use PT: for compensation (to attain standards set by the school curriculum) and for enrichment (to acquire additional knowledge over and above the school curriculum) (Buchman et al., 2010). These two types of PT may therefore be at least partly interpreted as responses to drawbacks in the GE system.

When extensively used as a compensatory function, PT may signal difficulties with the curriculum or particular areas of it, with the unsatisfactory quality of teaching resources (both human and material), or with the learning environment. These elements either alone or in combination may demonstrate the limited internal effectiveness of a GE system.

The prevalence of PT for enrichment purposes may illustrate a mismatch between the requirements of higher education (HE) entrance exams and the official school curriculum. In particular, the use of PT may be stimulated by the fact that university entrants are required to know more than is officially defined by the school curriculum. In this case, PT for enrichment points to a limited external relevance of the GE system.

It should be noted, however, that PT for enrichment and compensatory purposes cannot be attributed to drawbacks in mainstream education alone. Rather, the scope of the two types of PT mentioned above can be 
interpreted as a function of a complex interaction of educational drivers with other social, economic and cultural factors.

For example, in addition to deficiencies in mainstream schooling, the compensatory or enrichment PT may be driven by pupils' personal characteristics and learning abilities, an increased value of knowledge (a social factor) or the increased welfare of society (an economic factor). Therefore, careful analysis of the interrelation of different drivers is important in singling out the portion of PT that precisely reflects drawbacks in the formal education system as an open system. Academic literature suggests that educational factors are important drivers of PT, but there is still little quantitative research on what is the effect of educational factors on the overall scope of PT in different contexts and education systems. Our study adds to existing knowledge in the field through investigating the impact of educational factors on the patterns of PT in Georgia.

The following types of PT are used in this study as indicators of the inadequate quality of mainstream education: (i) compensatory PT that is driven by the irrelevance of system outputs to curriculum requirements; and (ii) enrichment PT that is driven by the irrelevance of the curriculum to the entrance requirements of the higher stages of formal education. The greater the scope of these types of PT in the country, the lower the quality of GE.

\subsubsection{Effects of PT on Education Systems}

One of the major concerns related to the effects of PT on education systems is the inequities that PT may generate or exacerbate in the formal education system.

When the GE system fails to meet quality criteria, PT enters the scene and compensates for these drawbacks. In many cases, however, some potential clients do not have access to a PT service because of financial or other reasons. Limited access to PT in this case leads to limited access to quality outcomes.

Prior research on shadow education in other countries finds that PT significantly increases inequalities in systems where high-stakes testing serves as a gatekeeper to future educational opportunities (Stevenson \& Baker 1992; Buchmann et al., 2010). Therefore, our study focuses on the transition point to higher education and evaluates the system against the criteria of equity by examining disparities in access to PT and the impact of PT on college enrolment in Georgia.

\subsection{PT: Local Context and Baseline Data}

The history of PT in Georgia dates back to the Soviet period. Although statistics are not available on PT from that time, it is thought that the practice was not widespread because the Soviet regime implicitly discouraged it as inequitable and only the elite could afford it (Silova et al., 2006).

The first ever attempt to measure the scope of PT in Georgia was made in 2004, thirteen years after the country gained its independence from Soviet rule, and took place within the framework of a large cross-national study of the phenomenon in six socialist and post-Soviet countries (see Note 1). The results brought alarming news to policy makers: 79 per cent of university entrants and students surveyed in Georgia were taking private lessons during the last year of secondary school. Georgia, along with Azerbaijan, significantly exceeded all other countries participating in the study (Silova et al., 2006). Furthermore, Georgia was the first in the list of these countries in terms of the intensity of utilization of the service (expressed in total hours of PT per week and the number of subjects). The study also indicated an earlier start and greater continuity in the use of PT in Georgia than in the other countries.

However, the results of the study were hardly surprising given the economic crisis and an unprecedented drop in education spending. During the first years of independence from Soviet rule, the share of spending on education as percentage of GDP fell from $7 \%$ to less than $1 \%$. This was an astonishing drop, "unique in the history of education systems worldwide" (Silova et al., 2006).

Underfinancing of the sector, weakened control of outputs and severe cuts in the salaries of schoolteachers and university professors led to a deterioration in the quality of education. Due to the critical state of the job market, education no longer served as a good predictor of income, but it still remained as a marker of social status. In response to the above trend, higher education became a major source of corruption (Hallak \& Poisson, 2007). Parents often sought tutoring for their children from professors who sat on admissions committees, in the expectation that answers to entrance examination questions would be provided or that favourable consideration would result (Janashia, 2004). According to a Transparency International report, "A student [could] practically buy his or her way through [an] institution, paying for every exam and, ultimately, a diploma" (Meier, 2004). 
Largely boosted by a World Bank loan of US\$ 45 million in 2004, Georgia started a comprehensive reform with the aim of reviving the education system in the country. Improving the quality of the outputs of general education and increasing equity in access to these outputs were considered as important goals of this reform (see Note 2).

The share of general education funding as a proportion of GDP increased from 2 per cent to almost 3 per cent, teacher salaries at least doubled, the general approach, as well as content and methods of teaching, were redefined by two new framework documents: National Goals of General Education and the National Curriculum. The emphasis in these documents was on a student-cantered approach and an outcome-based evaluation.

In order to reduce corruption at the entrance point to higher education institutions (HEIs), university-based entrance exams were replaced by the National Entrance Examinations, a computer-based, centrally administered aptitude test and exams in core subjects.

The structural and conceptual reforms in the general education (GE) sector aimed to decentralize power and to grant more rights to schools in making important decisions on the education process. The underlying assumption behind this approach was that a decentralization of power might lead to a diversified quality of outputs, thus creating precedents of good management at school level.

In order to balance the increased freedom of schools in decision-making, the Ministry introduced or (in some cases) intensified control mechanisms:

- On an input level, accountability mechanisms currently include a teacher certification procedure (introduced in 2010), exams for school principals (introduced in 2008), and a textbook approval procedure (introduced in 2005, and amended in 2010);

- On a process level, the Ministry of Education and Science (MES) enacted school authorization and accreditation systems along with an optional mechanism of so-called "school branding" that implies awarding stars to schools on the basis of certain criteria;

- On an output level, the MES imposed school exit exams in nine subjects (started in 2011).

All these measures were aimed at increasing the effectiveness of general education in Georgia. As we will see shortly, our new survey evidence illustrates how great the impact of the above changes was on patterns of PT in Georgia and gives insights that result in a deeper understanding of the current state of the general education system in terms of the criteria of equity and the quality of outputs.

\subsection{Current Study: Goals and Main Research Questions}

The goal of this study is to describe the scope, drivers and effects of PT in Georgia. It is hoped that the results of the study will bring additional insights for the evaluation of the quality and equity of the general education system in the country by providing answers to the following specific questions:

Does the perceived quality of general education have an effect on the overall scope of PT in Georgia?

What is the share of educational factors in the overall scope of the perceived drivers of PT?

Are there disparities in access to PT by different subgroups?

Does access to the PT service have an impact on the vertical mobility of university entrants?

If our findings suggest positive answers to the above questions, the scope of PT may serve as an indicator of the severity of quality and equity problems in the formal education system.

\section{Methodology}

The data for this article is derived from a nationwide survey of parents on the issue of private tutoring (conducted in September 2011). A total of 1,200 interviews were held in the capital and in all regions of Georgia among parents of pupils of elementary, basic and secondary levels of general education.

The 2002 population census was used as a sampling frame and a two-stage cluster design with preliminary stratification was applied as a sampling method. The basic assumption behind the sampling design was that the scope of PT might vary by level of general education and by location. Therefore, location (capital, urban, rural) and level of general education (primary: grades 1-6; basic: grades 6-9; and secondary: grades 10-12) were used as stratification variables. The census district served as the primary sampling unit and the household as the secondary one. The final sampling unit in our survey was the parent of a school-age child. The sampling error is $2.2 \%$ with a $95 \%$ confidence level. 


\begin{tabular}{|c|c|c|c|c|c|c|c|c|}
\hline \multirow[b]{2}{*}{ Regions } & \multicolumn{4}{|l|}{ Urban } & \multicolumn{4}{|l|}{ Rural } \\
\hline & 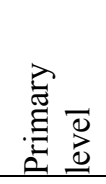 & 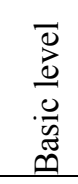 & 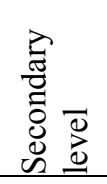 & 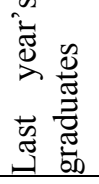 & 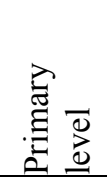 & $\begin{array}{l}\bar{D} \\
\vec{d} \\
0 \\
\frac{0}{\pi} \\
0 \\
0\end{array}$ & 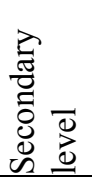 & 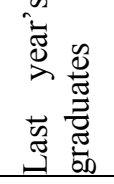 \\
\hline Capital & 100 & 100 & 100 & 100 & 0 & 0 & 0 & 0 \\
\hline Adjara & 12 & 12 & 13 & 13 & 7 & 8 & 7 & 8 \\
\hline Guria & 5 & 5 & 5 & 5 & 5 & 5 & 5 & 5 \\
\hline Imereti & 28 & 28 & 28 & 26 & 21 & 19 & 20 & 20 \\
\hline Kakheti & 7 & 8 & 7 & 8 & 17 & 18 & 18 & 17 \\
\hline Mtskheta-Tianeti & 3 & 2 & 2 & 3 & 6 & 5 & 5 & 4 \\
\hline Samegrelo & 15 & 15 & 15 & 15 & 12 & 12 & 13 & 13 \\
\hline Samtskhe-Javakheti & 5 & 5 & 5 & 5 & 7 & 8 & 7 & 8 \\
\hline Kvemo Kartli & 15 & 15 & 15 & 15 & 14 & 15 & 15 & 16 \\
\hline Shida Kartli & 10 & 10 & 10 & 10 & 11 & 10 & 10 & 9 \\
\hline Total & 200 & 200 & 200 & 200 & 100 & 100 & 100 & 100 \\
\hline
\end{tabular}

Our dataset included information on the financial status and patterns of expenditure of sampled households as well as on the education of respondents. Interviewees were asked whether their children used a private tutoring service during the previous school year and what were the main arguments behind the parental decision to engage in PT. Respondents were also asked to evaluate the overall quality of general education and the perceived need for PT in the country. Other questions in the survey gathered information on the type of school, the providers of PT as well as on the intensity of its use, its cost and the types of PT by subject. For those students who were entering the higher education stage, the results of the entrance exams were recorded as a dichotomous variable (enrolled/not enrolled).

Simple descriptive statistics were generated in the first phase of the analysis to describe the overall scope and patterns of use of PT in the country. Analysis of variance (ANOVA) and Chi square tests were applied to differentiate the patterns of use of PT by main stratification variable. We also analysed the structure of responses on the main drivers of PT to see if educational factors constituted a larger share in the total number of responses as compared to other factors.

Using binary logistic regression models we then estimated the effect of different factors on the likelihood of utilizing the service and measured the impact of PT on enrolment in higher education institutions.

\section{Results}

Currently every fourth student takes tutoring in Georgia. The scope of PT varies significantly by level of general education. The use of PT starts at the primary level (15\%), intensifies at basic level (37\%), grows further at secondary level (43\%) and reaches its highest point in the final year of schooling (57\%). The scope of PT differs significantly across different income groups. Table 1 provides a first-glance look at the incidence of PT in different groups of household income by levels of GE, illustrating that almost all students in the highest income group take PT lessons in the final year of general education.

Table 1. PT use by levels of general education and household income

\begin{tabular}{llllll}
\hline & higher income & moderate income & low income & Chi-square & Sig \\
\hline Primary & $24.4 \%$ & $18.3 \%$ & $11.1 \%$ & 8.331 & 0.008 \\
Basic & $72.7 \%$ & $37.3 \%$ & $20.9 \%$ & 51.162 & 0.000 \\
Secondary & $61.3 \%$ & $57.8 \%$ & $30.3 \%$ & 22.983 & 0.000 \\
Last grade & $86.9 \%$ & $72.0 \%$ & $36.5 \%$ & 53.512 & 0.000 \\
\hline
\end{tabular}


Simple cross-tabulations also suggest that the scope of PT differs by location and occurs more heavily in Tbilisi (the capital), urban and rural locations (in that order). However, significant differences are no longer evident after we control for household income.

In the Georgian context, we expected a PT service to be less utilized by private school pupils than by those in public schools because of the resource advantages enjoyed by students and teachers in the former. However, our analysis does not reveal significant differences in this respect.

The total parental expenditure on PT is equivalent to $35 \%$ of the State Budget for General Education. In the budget of families that have school-age children, expenditure on education is second only to that on food and the share of PT-related expenses forms $40 \%$ of total household expenditure on education.

The demand for private tutoring is even greater than actual indicators of the use of the service reveal. The necessity of private tutoring is confirmed by $90 \%$ of the total number of respondents. Some $60 \%$ of those who do not take private tutoring state a lack of funds as the only reason.

The average score for the quality of general education is 3 on a 5 -point scale, where 5 is the highest score. Table 2 illustrates significant differences in mean scores by level of general education, showing that the mean score is significantly lower in the upper levels of general education.

Table 2. Perception of the quality of education by GE level

\begin{tabular}{|c|c|c|c|c|c|c|}
\hline \multirow{2}{*}{ Level of GE } & \multirow{2}{*}{$\mathrm{N}$} & \multirow{2}{*}{ Mean } & \multirow{2}{*}{$\begin{array}{l}\text { Std. } \\
\text { Deviation }\end{array}$} & \multirow{2}{*}{$\begin{array}{l}\text { Std. } \\
\text { Error }\end{array}$} & \multicolumn{2}{|c|}{$\begin{array}{l}95 \% \text { Confidence } \\
\text { Interval for Mean }\end{array}$} \\
\hline & & & & & $\begin{array}{l}\text { Lower } \\
\text { Bound }\end{array}$ & $\begin{array}{l}\text { Upper } \\
\text { Bound }\end{array}$ \\
\hline Primary & 294 & 3.43 & 0.728 & 0.042 & 3.34 & 3.51 \\
\hline Basic & 294 & 3.31 & 0.726 & 0.042 & 3.23 & 3.39 \\
\hline Secondary & 302 & 3.31 & 0.784 & 0.045 & 3.22 & 3.4 \\
\hline Last grade & 300 & 3.26 & 0.671 & 0.039 & 3.19 & 3.34 \\
\hline Total & 1,190 & 3.33 & 0.73 & 0.021 & 3.29 & 3.37 \\
\hline
\end{tabular}

$\mathrm{F}=2.625$, Sig. 0.047

A majority of parents surveyed (85\%) think that the need for PT is generated by inconsistencies between the school education process and the official curriculum, while $27 \%$ attribute the need for PT to a mismatch between the requirements of HE entrance exams and the actual school curriculum. Socio-cultural factors (that is, the increased value of knowledge in society, PT being a "fashionable trend", or different parental reasons such as lack of time or knowledge to help a child) were mentioned by $45 \%$ of respondents. In sum, the factors related to drawbacks of the education system (operationalized in our study as an inconsistency between actual outputs and curriculum requirements and/or an inconsistency between the official curriculum and HE entrance requirements) form $72 \%$ of total number of responses on the main drivers of PT.

In the next stage of the analysis we estimated the effect of the perceived quality of GE and the economic status of a household on the likelihood of taking PT. Both predictors were coded as ordinal variables. The logistic model also included other independent variables such as a public/private school dummy, and location (capital -1, urban -2, rural -3). In order to capture some of the effects of socio-cultural factors on the probability of engaging in PT, two other predictors were added to the model: parental education (coded as an ordinal variable) and the proportion of education-related expenditures in total household expenditures (as a proxy of the value of a child's education in a household). 
Table 3. Effects of different factors on the likelihood of taking PT

\begin{tabular}{|c|c|c|c|c|c|}
\hline & & & $\mathrm{B}$ & S.E. & $\operatorname{Exp}(B)$ \\
\hline \multicolumn{3}{|c|}{ Parental education } & $0.421 * *$ & 0.15 & 1.524 \\
\hline \multicolumn{3}{|c|}{ Value of education in household } & $0.022 * * *$ & 0.004 & 1.022 \\
\hline \multicolumn{3}{|c|}{ School type (public/private) } & 0.388 & 0.271 & 1.474 \\
\hline \multicolumn{6}{|c|}{ Location (capital, urban, rural ) } \\
\hline \multicolumn{3}{|c|}{ Capital(1) } & -0.233 & 0.207 & 0.792 \\
\hline \multicolumn{3}{|c|}{$\operatorname{Urban}(2)$} & -0.042 & 0.184 & 0.959 \\
\hline \multicolumn{3}{|c|}{ Perceived quality of GE } & $-0.226^{*}$ & 0.106 & 0.798 \\
\hline \multicolumn{3}{|c|}{ Household economic status } & $0.493 * * *$ & 0.109 & 1.637 \\
\hline \multicolumn{3}{|c|}{ Constant } & -2.389 & 0.591 & 0.092 \\
\hline \multicolumn{6}{|c|}{$* \mathrm{p}<.05 ; \quad * * \mathrm{p}<.01 ; \quad * * * \mathrm{p}<.001$} \\
\hline \multicolumn{6}{|c|}{ Chi-square $\quad 178.259$} \\
\hline \multicolumn{6}{|c|}{$\begin{array}{ll}\text { Sig. } & 0.000\end{array}$} \\
\hline \multicolumn{2}{|c|}{-2 Log likelihood } & 1041.043 & & & \\
\hline \multicolumn{2}{|c|}{ Cox\&Snell R Square } & 0.176 & & & \\
\hline \multicolumn{2}{|c|}{ Neglkerke R Square } & 0.24 & & & \\
\hline
\end{tabular}

Table 3 reports the estimated coefficients and illustrates that the perception of the quality of school education has a significant negative impact on the likelihood of engaging in PT. The lower the quality of mainstream education in parents' opinion, the higher the probability of PT use.

The perception of children's education as a high priority by households has a significant, but small effect on the likelihood of utilizing PT. As expected, the public/private school divide exhibits no direct effect on PT use, nor does location increase the probability of utilization of the service.

Household income and parents' education, however, have the largest effect compared to other predictors in the model, illustrating that family background in general, and the financial resources of the household in particular, significantly boost the odds of using a PT service.

The last stage of our analysis estimated the impact of PT on the probability of enrolment in HE institutions. Another logistic regression model was built for this aim. This model included a PT dummy variable (PT utilized $=1$ ), public/private schools and parental education as ordinal variables, and the value of education in a household calculated as ratio of educational expenses to total household expenditure.

Table 4. Effects of different factors on likelihood of enrolment in HE institutions

\begin{tabular}{llll}
\hline & B & S.E. & $\operatorname{Exp}(\mathrm{B})$ \\
\hline PT & $0.891^{* *}$ & 0.367 & 2.437 \\
Private school (1) & -0.799 & 0.819 & 0.45 \\
Parental education & $-0.77^{*}$ & 0.341 & 0.463 \\
Value of education in a household & $-0.014^{*}$ & 0.006 & 0.986 \\
Constant & -0.122 & 1.059 & 0.885 \\
\hline
\end{tabular}

${ }^{*} \mathrm{p}<.05$, two-tailed; $* * \mathrm{p}<.01 ; * * * \mathrm{p}<.001$

$\begin{array}{ll}\text { Chi-square } & 28.067 \\ \text { Sig. } & 0.000 \\ \text {-2 Log likelihood } & 194.734 \\ \text { Cox\&Snell R Square } & .126 \\ \text { Neglkerke R Square } & .192\end{array}$


The results of this regression analysis illustrate a very sharp positive effect of PT use on the probability of enrolment in HE institutions. Socio-cultural factors, such as parental education and the value of education, have a significant but smaller effect on enrolment patterns.

\section{Conclusions and Discussion}

The scope of private supplementary tutoring has diminished in Georgia after comprehensive reform of the education system, but it still represents a substantial parallel activity to mainstream education. Serving as a mirror of the formal education system, it points to many remaining challenges and risks related to the reform of mainstream schooling in Georgia.

The first major conclusion derived from our analysis is that the low quality of mainstream education still serves as an important driver of PT. The prevalence of private tutoring for compensatory reasons at all stages of general education illustrates that, despite numerous structural and conceptual reforms, schools often fail to produce set outputs.

Scholarly work in other countries undergoing similar reforms in the education sector suggests that the roots of the problem might lie in the reform itself, thus pointing to some directions for further research on this issue. In particular, qualitative research on the phenomenon in different countries across Europe and in the post-Soviet countries illustrates that one of the reasons for the failure of schools to reach set outcomes is an overloaded and substantially stretched curriculum, a result of the recent curricular reforms. These curricular changes broaden academic horizons, but they also burden pupils. In addition, schools are encouraged to move from teacher-centred learning, which was common during the Soviet period, to student-centred learning, which may be more effective but which is challenging for teachers (Bray, 2011, Silova et al., 2006) as they find it difficult to assume new duties and obligations, or they have an excessive time lag in adopting changes (Kazimzade \& Lepisto, 2010). Although additional research is needed to test the above hypotheses in the context of Georgia, it is obvious from our research that some of the components of the reform have not resulted in the desired outcomes. Policy makers, therefore, can learn from experiences in which similar reforms of the curriculum have led to an expansion rather than a contraction of shadow education.

Although corruption had been reduced in the university entrance exams in Georgia (Transparency International, 2010, Bethell \& Zabulionis, 2008), our findings show that the need for PT is still extremely large at the transition point to higher education.

Our conclusions again coincide with results of scholarly research in different parts of the world showing that examinations at different levels are major drivers of the scale and shape of shadow education in Europe (Bray, 2011), Asia (Bray \& Lykins, 2012) and the United States (Buchmann et al., 2010). This study also adds to existing empirical evidence of the interrelation between high-stake examinations and the scope of PT by exploring specific factors influencing exam-driven PT in the Georgian context. Our study shows that the perceived mismatch between the content of the school curriculum and the entrance requirements to higher education prompts the need for PT. In order to reduce exam-driven PT in the country, policy-makers might consider checking the consistency of the official curriculum with the entrance requirements of the higher stages of formal education. Stakeholders at both sides of the gateway between these levels of formal education should clearly know what the requirements to pass the threshold are and they must be sure that these requirements are achievable within the process of mainstream schooling.

The findings of our study also raise concerns about the equity issue in the formal education system by adducing empirical evidence of the substantial influence of PT on enrolment in HE institutions in Georgia. The conclusions of this study bear important similarities to other studies in different parts of the world showing that disparities in access to PT by rich and poor lead to limited access to higher education for students with lower socio-economic status (Bray, 2011, Buchmann et al., 2010, Heyneman, 2011).

The results of this study are important to local policy makers in two ways:

Firstly, this study points to the existing drawbacks of the system and contributes to a broader analysis of mainstream education as a complex open system. Further research is needed, however, to disaggregate a broad concept of the quality of mainstream education to more specific aspects that perpetuate the use of PT across different subjects, grades and levels of general education, and incorporate more socio-cultural factors in the analysis of the drivers of PT. Future research might also examine the effect of PT on students' vertical mobility in more detail, preferably with data that can capture scores at entrance exams as well as the intensity and quality of private tutoring. 
Secondly, our research proves that data on PT can serve as a good indicator of the overall effectiveness of education systems, thus highlighting the importance of constant monitoring of the phenomenon. This report is based on a representative sample of parents of school-age children that describes the target population well in terms of income, location or level of general education, and can be used as a baseline for future analysis of PT dynamics in the country.

In addition to being informative to policy makers and scholars on a local level, increased knowledge on the particularities of the interrelation of PT and the formal education system in Georgia is also important to a broader discussion of the phenomenon. The use of private tutoring to supplement formal school education is an international education policy issue as the phenomenon appears to be growing in many countries of the world, both in absolute terms and relative to the formal education sector (Dang \& Rogers, 2008). Factors related to the education system are given a considerable place in the typology of the drivers of private tutoring in the academic literature, however, there is still little empirical evidence as to which specific characteristics of formal schooling shadow education responds to and how these characteristics function as drivers in different contexts (Bray, 2011; Baker et al., 2001). Our research represents an attempt to unfold the complex issue of the interplay of PT and formal education in Georgia and it captures an interesting moment of PT being reshaped in response to drastic on-going changes in the system.

\section{References}

Baker, D. P., \& LeTendre, G. E. (2005). National differences and similarities: World culture and the failure of schooling. Stanford: Stanford University Press.

Baker, D. P., Akiba, M., LeTendre, G. K., \& Wisseman, A. W. (2001). Worldwide shadow education outside-school learning: Institutional quality of schooling, and cross-national mathematics achievement. Educational Evaluation and Policy Analysis, 23(1), 1-17. http://dx.doi.org/10.3102/01623737023001001

Bethell, G., \& Zabulionis, A. (2008). The survey on attitudes towards the reform of examination systems in selected post-socialist countries in Europe. RE: FINE Project 'Assessment for increasing quality, equal opportunities and accountability in education'. Retrieved from http://www.soros.org/sites/default/files/assessement_20080101.pdf

Bray, M. (2003). Adverse effects of private supplementary tutoring: dimensions, implications, and government responses. Series: Ethics and Corruption in Education. UNESCO. Retrieved from http://unesdoc.unesco.org/images/0013/001330/133039e.pdf

Bray, M. (2011). The challenge of shadow education: Private tutoring and its implications for policy makers in the European Union. Retrieved from http://www.nesse.fr/nesse/activities/reports/the-challenge-of-shadow-education-1

Bray, M., \& Lykins, C. (2012). Shadow education: Private supplementary tutoring and its implications for policy makers in Asia. Retrieved from http://www.adb.org/publications/shadow-education-private-supplementary-tutoring-and-its-implications-pol icy-makers-asia

Bray. M. (2009). Confronting the shadow education system: What government policies for what private tutoring? International Institute for Educational Planning. UNESCO. Retrieved from http://www.iiep.unesco.org/fileadmin/user_upload/Info_Services_Publications/pdf/2009/Bray_Shadow_edu cation.pdf

Buchmann, C., Condron, D. J., \& Roscigno, V. J. (2010). Shadow Education, American Style: Test Preparation, the SAT and College Enrollment. Social Forces, 89(2), 435-462. http://dx.doi.org/10.1353/sof.2010.0105

Dang, H., \& Rogers F.H. (2008). How to Interpret the Growing Phenomenon of Private Tutoring: Human Capital Deepening, Inequality Increasing, or Waste of Resources?. The World Bank. Retrieved from http://elibrary.worldbank.org/content/workingpaper/10.1596/1813-9450-4530

Gharajedaghi J., \& Ackoff, R. L. (1984). Organisms and social systems, Strategic Management Journal, 5(3), 289-300. http://dx.doi.org/10.1002/smj.4250050308

Hallak, J., \& Poisson, M. (2007). Corrupt schools, corrupt universities: What can be done? International Institute for Eudactional Planning. UNESCO. Retrieved from http:/unpan1.un.org/intradoc/groups/public/documents/unesco/unpan025403.pdf

Heyneman, S. P. (2011). Private Tutoring and Social Cohesion, Peabody Journal of Education, 86(2), 183-188. http://dx.doi.org/10.1080/0161956X.2011.561662 
Janashia, N. (2004). Fighting corruption in Georgia's universities. Retrieved from http://www.aaup.org

Kazimzade, E., \& Lepisto, E. (Eds.). (2010). Drawing the line: Parental informal payments for education across Eurasia. Education Support Program of the Open Society Institute, Network of Education Policy Centers. Retrieved from http://www.soros.org/sites/default/files/drawing-line-20100308.pdf

Meier, B. (2004). Corruption in the education sector: An introduction. Transparency International and the Christian Michelsen Institute. Re from http://socialtransitions.kdid.org/sites/socialtransitions/files/resource/files/Meier2004C_Education\%20Corru ption.pdf

Silova, I., Budiene, V., \& Bray, M. (2006). Education in a hidden marketplace: Monitoring of private tutoring. Education Support Program of the Open Society Institute, Network of Education Policy Centres. Retrieved from http://www.soros.org/sites/default/files/hidden_20070216.pdf

Stevenson, D. L., \& Baker, D. P. (1992). Shadow Education and Allocation in Formal Schooling: Transition to University in Japan. American Journal of Sociology, 97(6), 1639-1657. Retrieved from http://www.jstor.org/stable/2781551

Transparency International Georgia. (2010). Setting Georgia's schools free? An assessment of whether decentralization reforms have made Georgian schools more accountable to their communities. Retrieved from http://transparency.ge/sites/default/files/post_attachments/School\%20Reform-ENG_0.pdf

\section{Notes}

Note 1. This survey was implemented by the International Institute for Education Policy Planning and Management (EPPM, Georgia) within the framework of a larger effort by the Open Society Institute (OSI) to compare quantitative data on PT in six countries, ( Georgia, Azerbaijan, Lithuania, Bosnia and Herzegovina, Croatia and Poland).

Note 2. The changes implemented in Georgia from 2004 through 2009 are reflected in the Georgian government programme approved in 2004. Expansion of this programme and detailed identification of the next priorities on the basis of progress achieved and new challenges encountered were presented in "The Basic Data and Directions of the Government of Georgia" for 2007-2010, 2008-2011, and 2009-2012. 